\title{
UNA MIRADA A LA INTERACCIÓN EN LAS REDES SOCIALES
}

\section{One view to the interaction in the social media}

Amaro La Rosa*

\begin{abstract}
Resumen
El artículo presenta una apreciación exploratoria sobre la interacción en las redes sociales. Se parte de una comparación entre las redes de jóvenes de los años 50 con las redes sociales en que interactúan en la actualidad. Se describe la naturaleza de la interacción en las redes sociales y los resultados de algunas investigaciones sobre el particular,
\end{abstract}

Palabras clave: Interacción, redes sociales, internet, comunicación.

\begin{abstract}
The article presents an exploratory approach on interaction in the social media. The author starts from one comparison between the street corner society of the 50's and the contemporary interaction in social networking. Nature of interaction and some research results of this issue are described.
\end{abstract}

Keywords: Interaction, social media, internet, communication.

\footnotetext{
* Psicólogo. Periodista. Docente Universidad Femenina del Sagrado Corazón. amaro@unife.edu.pe
} 
Las redes sociales tienen un rol muy importante entre los recursos de Internet. Basta para ello con remitirnos a las cifras. Hacia abril de 2016 Facebook contaba con mil quinientos noventa millones de usuarios a nivel global (Statista.com, 2016). A marzo del 2016 Facebook registraba mil millones 90 mil usuarios diarios. De ellos, 989 millones eran usuarios activos a través de teléfonos móviles inteligentes (Facebook, 2016). Entretanto, WhatsApp cuenta con 1,000 millones de usuarios, Instagram 400 millones y Twitter 340 millones de usuarios activos (Statista.com, 2016).

Por cierto no son solamente números. Lo que podemos denominar una cultura de las redes sociales caracterizada por la interactividad es compartida por un número creciente de personas en el mundo entero. Los nativos digitales son efectivamente mayoría en las redes sociales, pero también se incrementan los migrantes digitales incluyendo a las personas de la tercera edad quienes encuentran en las redes una solución para establecer y mantener modalidades de interacción que les permiten sobrellevar de mejor manera los avatares de la soledad y la pérdida de contactos de su generación.

\section{DE LA SOCIEDAD DE LAS ESQUINAS AL MUNDO DIGITAL}

Street Corner Society fue una obra escrita por el sociólogo norteamericano William Foote Whyte que se convirtió en best seller en el año 1955. Relataba el comportamiento social de grupos juveniles en las esquinas de las calles de Boston, una de las ciudades más antiguas de los Estados Unidos.

Si nos trasladamos mentalmente a ese mismo año, en las esquinas de los barrios de Lima, de diversos sectores sociales, se reunían con frecuencia grupos de jóvenes, para conversar durante largas horas. Esta modalidad de intercambio era parte de su proceso de socialización, en el cual los grupos pares son importantes agentes. Habitualmente se mantenían como parte de un grupo que contaba con patrones de comportamiento estandarizados y normas éticas propias para el intercambio social. Así, guardaban respeto hacia los demás, especialmente hacia los mayores, lo que evidenciaba en cambios en su habla al acercarse un adulto.
En esa sociedad de las esquinas los jóvenes intercambiaban ideas acerca de todo, pero las relaciones con el sexo opuesto ocupaban un lugar especial. Se contaban experiencias reales y seguramente fantasías sobre el sexo así como sus primeros avatares en ese terreno, en una sociedad altamente conservadora como la de aquella época. Las aventuras y desventuras de los integrantes del gang se comentaban y recreaban asî como también eran motivo de bromas y chascarros. Se analizaba el comportamiento en fiestas y paseos que eran los lugares comunes de encuentro con las damiselas, a quienes en muchos casos habitualmente ni siquiera se tuteaba en las primeras ocasiones. Las adolescentes, en cambio se reunían en la casa de alguna de ellas para conversar, pues la calle no era un lugar que se percibiera como apropiado para ellas.

Hoy, seis décadas después, ya no es frecuente ver a esta clase de grupos en las esquinas que para usar los términos actuales se estaban comunicando offline. Los adolescentes se socializan en gran parte interactuando con sus pares a través de las redes virtuales en las cuales, como nativos digitales, suelen ser muy diestros. En la era digital, lo que se publicó en Facebook allí quedó y no puede borrarse, de tal modo que "el pasado" de la persona quedó registrado para siempre en un enorme archivo al cual cualquier usuario tiene libre acceso; más aún los contactos que la persona previamente ha aceptado. No hay lamento que valga y por eso la discreción es algo que no debe olvidarse. Todo depende por cierto de cada persona, pues para algunos seres humanos el llamar la atención de los demás es lo más importante, sin interesar cómo se logre.

Hoy en día los encuentros se publican en el Facebook, donde muchos no tienen reparos en relatar "para todo el mundo "lo felices o infelices" que son. Las personas escriben en su biografía "En una relación con..." y lo acompañan con una foto en pareja. Pero tal como le escuchaba no hace mucho a nuestra buena amiga Fátima Saldonid (2015), se trata de "amores de Facebook" donde todo es felicidad y donde podemos decir nosotros que la fantasía y el oropel suelen ser componentes comunes.

Antaño cuando una relación terminaba solían romperse las fotos y eliminarse todo lo que representara 
vestigio del compromiso, como si en términos reales se cumpliera con las palabras de una canción de moda en la Lima de los 80, la cual repetía el estribillo "Que no quede huella... que no que no...que no quede huella".

Naturalmente, hay quienes cuentan sus desventuras y se desgarran las vestiduras durante el normal duelo por la separación de la pareja, casi tal como una telenovela. En esto hay algo común con el intercambio social cotidiano, al margen de las redes. Hay quienes viven guardando celosamente su vida personal así como sus fracasos y por lo contrario, quienes se lamentan permanentemente como estilo de vida como buscando que el mundo los consuele y les tenga permanente compasión, tal como pasa con los hipocondriacos quienes sufren con enfermedades imaginarias que ni el mejor médico podrá curar.

Tal como en las relaciones offline, en el mundo online y en las relaciones establecidas a través del Facebook, existen personas que se engañan con respecto al tipo de relación que establecen. Así, dicen tener 200 o 400 amigos cuando lo que realmente tienen son simplemente contactos a la mayoría de los cuales jamás ha visto en persona. Se trata del fenómeno de trivialización de la amistad del que ya han hablado previamente diversos autores, según el cual se ubica en la categoría de amigo a personas con quienes solamente existe el rasgo común de pertenencia a una misma red social y ninguna vinculación real en la práctica, pues en muchos casos ni siquiera es el vecino amable a quien saluda todos los días al cruzarse en su recorrido habitual. Luego de su periplo por unos cincuenta países, investigando la realidad de Internet, Martel (2015) anota en el epílogo de su libro: "Las redes sociales multiplican los amigos virtuales, los que uno no conoce y no importa que eso pueda engendrar nuevas vulnerabilidades para los individuos y amenazas inéditas para su vida privada". Y esto porque paradójicamente se evidencia una mayor autoapertura en los posts de Facebook, en los tuits o en las fotos de Instagram.

Los escolares jóvenes están reunidos desde muy temprano en la mañana y charlan desde antes de iniciarse las actividades académicas. Sin embargo apenas traspasan la puerta del colegio empiezan a comunicarse de modo digital usando alguno de los recursos de sus móviles, acortando distancias para comentar lo que pasó en el día y probablemente para recordar las travesuras o los logros que alcanzaron en esa jornada o quien sabe para compartir datos o aclarar algún asunto que no les convenció durante la jornada y que alguno de los alumnos destacados del salón de clases se ha encargado de buscar en el ciberespacio, para que no queden dudas. Entre estos jóvenes existe diversidad de recursos para el intercambio de información. Sobre el particular nos parece conveniente citar el criterio de Chambers (2013) quien afirma que cuanto más estrecha es la vinculación entre los individuos mayor es el rango de canales o plataformas con las cuales cuentan para su interacción.

\section{APUNTES SOBRE LA INTERACCIÓN EN LAS REDES SOCIALES}

La interacción es una actividad básica, observable en los actores sociales en todas las sociedades, en el marco de la cual se vinculan entre sí dos o más de ellos. Para la visión del interaccionismo representa un rasgo común de la humanidad, constituyendo la base de su comportamiento en sociedad. Tanto más para este enfoque, es evidente que la propia sociedad en general se crea y construye en tanto los individuos o conglomerados de los mismos desarrollan un sinnúmero de interacciones de diversas características, intermediados o no por las instituciones sociales. Es en ese intercambio que se configura y reconfigura la simbolización de larealidad,creándose y modificándose los significados.

El concepto de interacción no tiene una connotación universal para todos los autores. A decir de Degenne (2009:66) "la interacción puede designar un intercambio elemental, de corta duración y representar una unidad de acción. En cambio, empleamos relación para aludir a un conjunto de interacciones entre las mismas personas a lo largo del tiempo". Vale decir que la interacción es eventual mientras que la relación supone cierto nivel de involucramiento.

Para Charon (2009) la interacción implica:

- La interacción consigo mismo: Aquella que se expresa en la reflexión personal

- La interacción social: La relación con otros individuos 
Las características de la interacción en el caso de las redes sociales no la hacen equivalente a la que se produce en la comunicación interpersonal cara a cara. Para la visión de Carpentier (2015) correspondería a una interacción usuario-sistema al implicar el uso de tecnología. Por nuestra parte estimamos que también podría ubicarse en lo que en términos generales se denomina comunicación mediada por computadoras (CMC) en la cual si bien se establece una interacción entre seres humanos, ésta se hace efectiva de modo distinto pues se produce necesariamente con la intermediación de equipos computarizados. Concordando con Kožuh, Jeremić, Sarjaš, Lapuh Bele \& Debevc (2015) en el marco de la CMC el otro (interlocutor) podría ser percibido de modo menos realista. Entenderíamos que ello se vincula necesariamente con la falta de las claves no verbales que son recursos vitales en la comunicación interpersonal y que complementan la comprensión de lo comunicado. Por cierto los emoticones tienen la intencionalidad de agregar sentido, pero constituyen en todo caso recursos artificiales que se agregan a posteriori.

Martínez, Solano y Amat (2012) a partir de una investigación con estudiantes españoles describen cuatro modalidades de interacción social mediada por las tecnologías:

- Modelo de costumbres: Se mantiene la misma red de contactos para la interacción presencial, móvil y en Internet. Usa la tecnología como complemento para la interacción.

- Modelo de costumbres tecnológicamente ampliado: Se mantiene la red de contactos de interacción personal que se refuerzan con la tecnología. Se establecen contactos de exclusiva interacción online.

- Modelo tecnológico: Se diferencian claramente contactos de interacción personal junto con un elevado número de contactos que se configuran y funcionan a partir de la red.

- Modelo multirrelacional: Se incrementan notoriamente las interacciones exclusivas en la red. Solo se interactúa en persona con algunos individuos.
Algunos autores sostienen que la teoría de Goffman puede muy bien ser aplicada para la comprensión de los procesos de interacción online que se hacen efectivas en las actividades de las redes sociales. Así, es posible explicar las estrategias de auto-presentación de las personas en Facebook. Desde la visión de Zhargouni (2007) ello se sustenta en que los mecanismos de auto - presentación son una parte importante de nuestra vida cotidiana y están tan anclados en el autoconcepto que son usados como patrones para la actuación en diversas situaciones. Esto permite entender por qué las personas suelen emplean como portada de Facebook imágenes relacionadas con sus intereses, motivaciones y experiencias de vida. Inclusive, en algunos casos emplean el Photoshop para retocar su retrato. Las nuevas formas de auto-presentación en Facebook son estudiadas por Mehdizadeh (2010) en un grupo de 100 usuarios de esta red social. Encuentra que los individuos con alta tasa de narcisismo y baja autoestima registran una constante actividad en redes sociales usando contenido auto promocional.

Ante situaciones de aislamiento social, que involucra limitaciones en la interacción social, el individuo se siente motivado a buscar recursos compensatorios que cubran el vacío que experimentan. Knausenberger, Hellmann \& Echterhoff (2014) estiman que el uso de Facebook activa pensamientos de estar conectados al crearse y mantenerse relaciones interpersonales y que podría bastar la sutil recordación de la red social y su pertenencia a la misma para superar el aislamiento online.

El estudio de Bussenius y Palacios (2012) sobre jóvenes marginales de la caleta Recoleta en Santiago de Chile muestra las modalidades de uso del Facebook como recurso de interacción para recuperar los lazos sociales perdidos con sus familiares. Establecen relaciones online aun cuando a decir de las autoras la interacción offline sea bastante precaria, por su estilo de vida y por su extrema pobreza, entre otros factores.

Hogan (2010), por su parte, entiende que la autopresentación en las redes sociales se explicita en:

- Desempeño: En "situaciones" sincrónicas (chateo). Tal como se hace efectivo en el inbox de Facebook. 
- Artefactos: En “exhibiciones" asincrónicas (actualización de estatus, sets de fotos). tPosts subidos a Facebook, el perfil en Twitter, fotos subidas a la cuenta de Flickr o la subida de videos a Youtube

Murthy (2012) estima que en el uso de Twitter se hace patente la auto-presentación. Los tuits reflejan la identidad de las personas, involucrando una manera de presentarse a sí mismos en el ciberespacio. La rutinaria actividad cotidiana de tuitear desempeña igualmente un rol importante para la ego-afirmación.
Para explicar la interacción en las redes sociales hemos propuesto un modelo relativamente sencillo según el cual cada persona posee un conjunto de rasgos psicológicos (personalidad, intereses, motivaciones, autoestima, etc.), vive en una sociedad en particular que cuenta con ciertos rasgos culturales, patrones de interacción, normas y valores, se encuentra en interacción con otros, muestra sus propias formas de interacción online y patrones de uso de redes sociales. Naturalmente, nuestro modelo representa solamente la aproximación a una maraña sumamente compleja de modalidades de interacción que se producen en la realidadentre individuosquienesparticipanactivamente en las redes sociales. La clara comprensión de esta interacción no es posible hacerla desde el paradigma de una disciplina aislada, sino desde una perspectiva transdisciplinaria.

Gráfico 1. Individuo interactuando con las redes sociales. Elaboración del autor

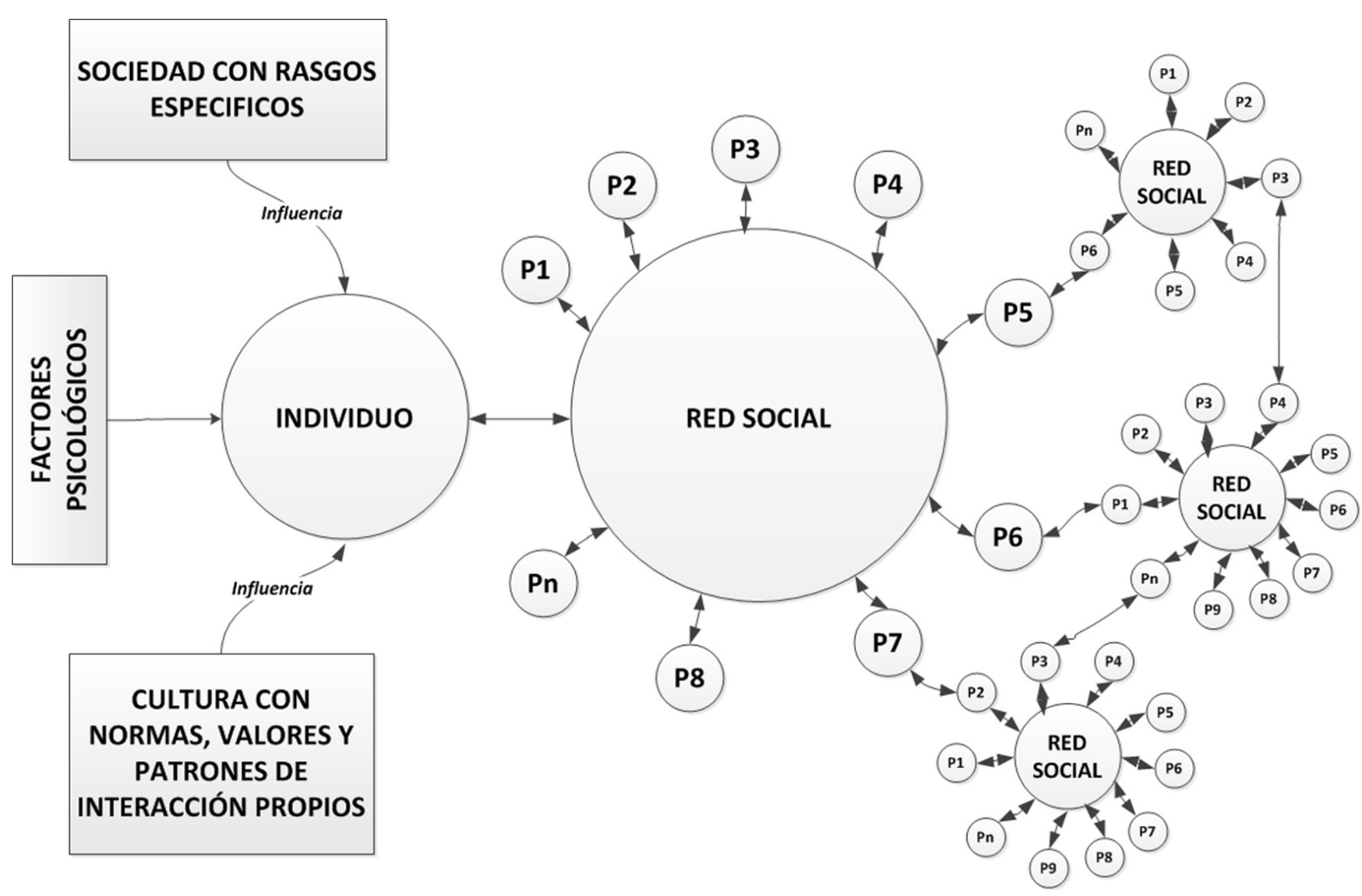


Coincidimos en este modelo con Primo (2007) cuando sostiene que la interacción social se caracteriza por: Mensajes intercambiados, interagentes quienes se encuentran en un contexto determinado y modalidad de relación colectiva construida entre los interlocutores. Nuestro enfoque, de naturaleza transdisciplinaria, se aproxima igualmente en cierto sentido al de Castells (2012:23) cuando afirma que "Los seres humanos construyen los significados en su interacción con el contexto natural y social, interconectando sus redes neuronales con las redes naturales y las redes sociales. Esta interconexión se hace efectiva por medio de los actos de comunicación".

Para Rincón (2009:79) Facebook está modificando la manera en que las personas interactúan en sociedad, al punto de haberse convertido en "un puente que permite establecer interacciones con un gran grupo de personas, a diferentes niveles de cercanía y familiaridad." Es bien cierto que millones de personas en el mundo entero se ponen en contacto sin que ello suponga necesariamente una interacción presencial.

A partir de la interacción social y dado que han crecido en un mundo de tecnología omnipresente se construye en los jóvenes una cultura digital que según diversos autores tiene una vigencia global y donde la interacción necesariamente supone lo virtual. Para decirlo en palabras de Crovi y López (2014:6): “A nuestro juicio, si en las prácticas culturales cotidianas de los jóvenes muchas de esas interacciones se llevan a cabo mediadas tecnológicamente, configuran una cultura fuertemente determinada por lo digital y en su visión del mundo ambos elementos (interaccióndigitalización) están interrelacionados".

Para Pfeiffer, Timmermans, Vogeley, Frith \& Schilbach (2013) desde la perspectiva de la neurociencia, existe una marcada diferencia cuando solo observamos que cuando estamos involucrados con otros en una interacción en tiempo real, dado que por su propia naturaleza, existe una motivación a ser receptivo.

Proponen que el conocimiento del otro en la interacción online se basa en la dinámica de la interacción establecida, en este caso en la interacción en redes sociales.
Las plataformas de redes sociales facilitan que los individuos tomen parte de manera bastante amigable en intercambios con sus amigos y familiares o puedan establecer contactos en redes más amplias. Con la contribución de los recursos de medios sociales, Internet está cambiando rápidamente las modalidades de consumo de las noticias. Howe (2011) determina que los individuos son primariamente motivados a compartir historias noticiosas con sus redes sociales, porque desean permanecer conectados con los otros y mantener las relaciones, lo cual extrapolado a nuestra temática explicaría la forma de interactuar de individuos interesados en la actualidad.En todo caso esta motivación de mantenerse conectados permanentemente deviene actualmente es una constante que hemos observado de manera persistente en los nativos digitales y en una tendencia creciente entre los migrantes digitales.

Pero ¿Cómo se decide en cuál de las redes sociales interactuar en determinado momento?

Skvoretz. \& Fararo (2016) formulan un enfoque al que denominan "Interaccionismo estocástico" el cual plantea que cuando los grupos se enfrentan a una serie de situaciones alternativas de índole social realiza una elección al azar a partir de criterios que han estandarizado previamente. Extrapolando este criterio al caso de la selección individual de las redes sociales, al encender su computadora un individuo cuenta con la posibilidad de elegir entre las diversas las redes sociales a las cuales está suscrito. La decisión se adopta dependiendo de sus intereses personales, motivación, Naturalmente que en cada individuo se materializarán tendencias en función de sus experiencias previas así como de las necesidades concretas de la coyuntura personal por la cual atraviesa.

\section{REFERENCIAS}

Bussenius, D y Palacios, M. (2012) Jóvenes excluidos y su experiencia en Facebook: Caso de Jóvenes Indigentes en Chile. Ponencia presentada en el 14 Encuentro Latinoamericano de Facultades de Comunicación Social, Lima, Octubre

Carpentier, N. (2015) Differentiating between access, interaction and communication, Conjunctions: Transdisciplinary journal of Cultural Participation, 2 (2), 7-28. Acceso: 14 de mayo de $2016 \mathrm{http}: / / \mathrm{www}$. conjunctions-tjcp.com/article/view/23117/20193 
Castells, M. (2012) Redes de indignación y esperanza: Los movimientos sociales en la era de Internet. Madrid: Alianza Editorial

Chambers, D. (2013) Social Media and Personal Relationships Online Intimacies and Networked Friendship, London: Palgrave Macmillan

Charon, J. M., (2009). Symbolic Interactionism: an Introduction, an Interpretation, an Integration, London: Pearson

Crovi, D. \& López R. (2014) Interacción en redes sociales digitales: Jóvenes trabajadores y estudiantes describen sus prácticas en red. Ponencia en el XII Congreso de la Asociación Latinoamericana de Investigadores de la Comunicación, Lima, agosto

Degenne, N. (2009) Types d'interaction, formes de confiance et relations. REDES, Revista hispana para el análisis de redes sociales, 16 (3), 63-92. Acceso: 11 de junio de 2016

http://revista-redes.rediris.es/pdf-vol16/vol16_3f.pdf Facebook (2016) Stats). Acceso: 19 de junio de 2016 http://newsroom.fb.com/company-info/

Hogan, B. (2010) The Presentation of Self in the Age of Social Media: Distinguishing Performances and Exhibitions Online Bulletin of Science Technology Society vol.30 no. 6, 377-386

Howe, J. (2011) Social media and news consumption. Thesis, Master of Arts in Communication and Leadership Studies, Gonzaga University

Knausenberger, J., Hellmann, J. \& Echterhoff, G. (2014) When virtual contact is all you need: Subtle reminders of Facebook preempt social-contact restoration after exclusion, European Journal of Social Psychology. 45 (3), 279-284

Kožuh, I., Jeremić, Z., Sarjaš, A., Lapuh Bele, J., Devedžić, V., \& Debevc, M. (2015) Social Presence and Interaction in Learning Environments: The Effect on Student Success. Educational Technology \& Society, 18 (1), 223-236.

Martel, F. (2015) Smart, Internet(s): la investigación. Buenos Aires: Aguilar, Altea, Taurus, Alfaguara

Martínez, F., Solano, I. y Amat, L. (2012) Análisis de mapas de interacción social en contextos virtuales para la reinterpretación de las relaciones en la escuela, Revista Latinoamericana de Tecnología Educativa, Vol 11(1). 13-26

Mehdizadeh S. (2010) Self-presentation 2.0: narcissism and self-esteem on Facebook Cyberpsychology, Behavior and Social Networking, 13(4), 357-364

Murthy, D. (2012) Towards a sociological understanding of social media: Theorizing Twitter. Sociology, 46 (6), 1059-1073

Pfeiffer, U., Timmermans, B, Vogeley, K., Frith, C \& Schilbach, L. (2013) Editorial: Towards a neuroscience of social interaction, Frontiers in Human Neuroscience, Vol 7, 1-2 doi: 10.3389/ fnhum.2013.00022

Primo, A. (2007) O aspecto relacional das interações na Web 2.0. E- Compós (Brasília), v. 9, p. 1-21. Acceso 1 de marzo de 2016 http://www.ufrgs.br/limc/PDFs/ web2.pdf

Rincón, SA. (2009) Interacción social virtual y comunicación interpersonal en dos escenarios de la Web 2.0: Narratopedia y Facebook. Tesis de grado en Comunicación, Facultad de Comunicación y Lenguaje Pontificia Universidad Javeriana

Saldonid, F. (2015) Comunicación personal

Skvoretz, J. \& Fararo, T. (2016) Status and Interaction: A Stochastic Model for the Measurement of Macrostatus Value and the Determination of Microstatus Ranking in Task Group Interaction, Socius: Sociological Research for a Dynamic World, Volume 2, 1-16. Acceso:10 de junio de 2016 http:// srd.sagepub.com/content/2/2378023115621561. full.pdf+html

Statista.com (2016) Leading social networks worldwide as of April 2016, ranked by number of active users (in millions). Acceso: 10 de junio de 2016 http:// www.statista.com/statistics/272014/global-socialnetworks-ranked-by-number-of-users/

Zhargouni, S. (2007) A Study of Self-Presentation in Light of Facebook. Oslo: Institute of Psychology, University of Oslo, Autumn. 